\title{
MRAS Speed Sensorless Vector Control of Induction Motor Drives Using Predictive Adaptation Mechanism
}

\author{
Moustafa Zair, Abdeldejbar Hazzab \\ Department of Electrical Engineering, Laboratoire Commande, Analyse et Optimisation des Systèmes \\ Electro-Energétiques, Tahri Mohammed University, Bechar, Algeria
}

\begin{tabular}{l} 
Article Info \\
\hline Article history: \\
Received May 2, 2018 \\
Revised Aug 23, 2018 \\
Accepted Sep 14, 2018 \\
\hline
\end{tabular}

Keyword:

Sensorless

Induction motor

Vector control

Classical MRAS

Predictive MRAS

\begin{abstract}
Recently of the main topic of research is the sensorless vector control of induction motor drive, In this paper presents the predictive model reference adaptive system (PMRAS) rotor speed observer, This observer developed from the classical MRAS rotor flux scheme associated with predictive adaptation mechanism designed from the Finite Control Set Model Predictive Control (FCS-MPC) by using a search optimization algorithm for calculate the rotor position which guarantee a minimum speed tuning error signal at each sampling period. The effectiveness of the proposed observer proved with the simulation results, show high dynamic performance speed and position observed in sensorless vector control process at low and zero speed as well robustness against motor parameter variation with different loading conditions.
\end{abstract}

Copyright $(2018$ Institute of Advanced Engineering and Science. All rights reserved.

\section{Corresponding Author:}

Zair Moustafa,

Department of Electrical Engineering,

Laboratory (CAOSEE), Tahri Mohammed Bechar,

Street of independence, BP 417, Bechar, Algeria.

Email: zairm29@yahoo.fr

\section{INTRODUCTION}

Induction motors and the field-oriented control (FOC) are widely used in various modern high performance drive application and acceptance in the electric drives markets worldwide [1],[2]. For many years, lots of efforts have been made in ac drives to eliminate the speed sensor mounted on the machine shaft this technology is referred as sensorless control [3]. In sensorless IM drives, several techniques have been proposed for rotor speed estimation such as extended kalman filter [4], sliding mode control [5], MRAS [6], artificial intelligence-based estimators [7] and direct calculation method.This models suffer from many problems which become dominant at low speed range including sensitivity to machine parameter variation, pure integration effects and inverter nonlinearity. Among these techniques, model reference adaptive system MRAS schemes are the most common strategies employed due to their relative simplicity and low computational effort [8],[9]. Rotor flux, back electromotive force (EMF) and reactive power.

Recent research activities in the use of predictive control techniques with sensorless applications [10]-[13]. In this study presented, the predictive MRAS speed observer based from the classical MRAS rotor flux scheme associated with the adaption mechanism designed from the Finite Control Set Model Predictive Control (FCS-MPC) by using a search algorithm developed to ensure the rotor position each sampling time and minimizing the speed tuning error signal to solve the problems associated with the adaption mechanism design [14]. The simulation results show improved performance of the predictive MRAS scheme at low speeds and with different loading also improves the system robustness against motor parameter variations. The paper is organized as follows; first, start with model of IM, IFOC vector control strategy and the convontional rotor flux MRAS observer. Then, a predictive MRAS used the voltage model of the classical 
MRAS and the current model represent in the rotor reference frame. This combination realized a robust observer. After that, the simulation resules are presented. Finally some concluding remarks are stated.

\section{MATHEMATICAL MODELS IMS AND VECTOR CONTROL}

\subsection{The IM Model}

After use the vector control, the induction machine can be represented as a two-phase motor in a stationary reference frame $(\alpha, \beta)$ and then convert in synchronously dynamic reference frame $(d, q)$ by applying Park transformation. The mathematical models of an IM can be described by the following state equations [4],[7],[15],[16].

$$
\begin{aligned}
& \dot{X}=A X+B U \\
& Y=C X
\end{aligned}
$$

With $X$ : state variables, $A$ : system evolution matrix, $B$ : control vector, $U$ : input vector it is represented by the tension vector.

$$
\begin{aligned}
& X=\left[\begin{array}{l}
i_{s d} \\
i_{s q} \\
\phi_{r d} \\
\phi_{r q}
\end{array}\right], \quad U=\left[\begin{array}{l}
V_{s d} \\
V_{s q}
\end{array}\right], B=\left[\begin{array}{ll}
b & 0 \\
0 & b \\
0 & 0 \\
0 & 0
\end{array}\right], C=\left[\begin{array}{llll}
1 & 0 & 0 & 0 \\
0 & 1 & 0 & 0
\end{array}\right], A=\left[\begin{array}{cccc}
a_{1} & \omega_{s} & a_{2} & a_{3} \\
-\omega_{s} & a_{1} & -a_{3} & a_{2} \\
a_{4} & 0 & a_{5} & \omega_{s l} \\
0 & a_{4} & -\omega_{s l} & a_{5}
\end{array}\right] \\
& a_{1}=-\frac{1}{\sigma L_{s}}\left(R_{s}+\frac{L_{m}^{2}}{T_{r} L_{r}}\right), a_{2}=\frac{L_{m}}{\sigma T_{r} L_{r} L_{s}}, a_{3}=\frac{L_{m}}{\sigma L_{s} L_{r}} \omega_{r}, a_{4}=\frac{L_{m}}{T_{r}}, a_{5}=-\frac{1}{T_{r}}, b=\frac{1}{\sigma L_{s}}, \\
& \omega_{s l}=\omega_{s}-\omega_{r}, \sigma=1-\frac{L_{m}^{2}}{L_{s} L_{r}}, T_{r}=\frac{L_{r}}{R_{r}}, T_{s}=\frac{L_{s}}{R_{s}}
\end{aligned}
$$

The mechanical equation is

$$
J \frac{d \Omega}{d t}=C_{e}-C_{r}-f \Omega
$$

Where the electromagnetic torque is

$$
C_{e}=\frac{3 P L_{m}}{2 L_{r}}\left(\phi_{r d} i_{s q}-\phi_{r q} i_{s d}\right)
$$

where $i_{s d}, i_{s q}$ are the direct and quadrature stator current; $\phi_{r d}, \phi_{r q}$ are the direct and quadrature rotor flux; $V_{s d}$, $V_{s q}$ are the stator voltage, all expressed in a dynamic reference; $L_{m}$ is the machine mutual inductance; $L_{s}$ is the stator inductance; $L_{r}$ is the rotor inductance; $R_{r}$ is the rotor resistance; $R_{s}$ is the stator resistance; $\omega_{s l}$ is slip pulsation; $\omega_{s}, \omega_{r}$ are the stator and rotor pulsation; $\Omega$ is rotor speed; $C_{e}$ is the electromagnetic torque; $C_{r}$ is the load torque; $J$ is inertia; $f$ is friction factor; $P$ is the number of pole pairs; $T_{r}$ rotor time constant; $T_{s}$ stator time constant; $\sigma$ is the leakage coefficient .

\subsection{Idirect Rotor Flux Orientation control}

The purpose of the flux rotor orientation is to decouple the stator current into flux and torque producing components, regulated separately, to obtain a good performance IM drive [7],[17],[18]. For vector control, the rotor flux is oriented in the d-axis

$$
\phi_{r q}=0, \phi_{r d}=\phi_{r}
$$


The slip frequency is obtained as

$$
\omega_{s l}=\frac{L_{m}}{\phi_{r} T_{r}} i_{s q}
$$

The electromagnetic developed torque equation is given by

$$
C_{e}=\frac{3 P L_{m}}{2 L_{r}} \phi_{r d} i_{s q}
$$

\section{THE ROTOR FLUX MRAS OBSERVER}

The conventional rotor flux MRAS speed observer shown in Figure 1. It usually consists of two mathematical models, the reference and adaptive models, and an adaptation mechanism to generate the observer speed.

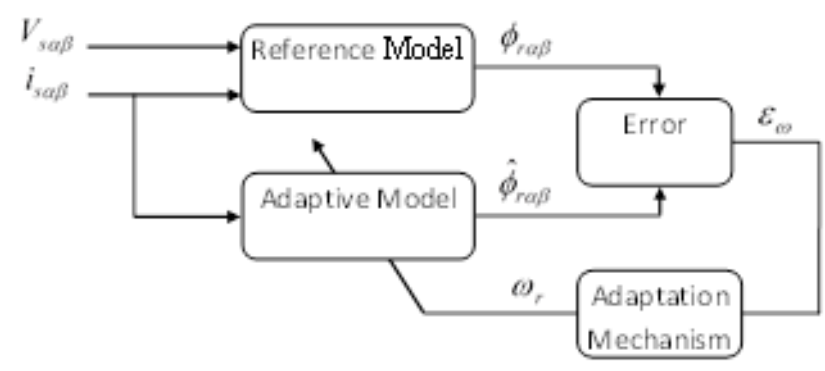

Figure 1. The classical rotor flux MRAS observer

The reference model represents the stator voltage equation in the stator reference frame, It generates the reference value of the rotor flux component from the monitored stator voltage and current components which can be written as [3],[19]-[21].

$$
\begin{aligned}
& p \phi_{r \alpha}=\frac{L_{r}}{L_{m}}\left(V_{s \alpha}-R_{s} i_{s \alpha}-\sigma L_{s} p i_{s \alpha}\right) \\
& p \phi_{r \beta}=\frac{L_{r}}{L_{m}}\left(V_{s \beta}-R_{s} i_{s \beta}-\sigma L_{s} p i_{s \beta}\right)
\end{aligned}
$$

where $\phi_{r \alpha}, \phi_{r \beta}$ are the alpha and beta referance rotor flux components; $i_{s \alpha}, i_{s \beta}$ are the stator current; $V_{s \alpha}, V_{s \beta}$ are the stator voltage, all expressed in a stationary reference; $p$ is the laplacian.

The adaptive model represents the current model, describes the rotor voltage equations in the stator reference frame where the rotor flux components are expressed in terms of stator current components and the rotor speed. The rotor flux components are given by [3],[19]-[21].

$$
\begin{aligned}
& p \hat{\phi}_{r \alpha}=\frac{L_{m}}{T_{r}} i_{s \alpha}-\frac{1}{T_{r}} \hat{\phi}_{r \alpha}+\omega_{r} \hat{\phi}_{r \beta} \\
& p \hat{\phi}_{r \beta}=\frac{L_{m}}{T_{r}} i_{s \beta}-\frac{1}{T_{r}} \hat{\phi}_{r \beta}+\omega_{r} \hat{\phi}_{r \alpha}
\end{aligned}
$$

where $\hat{\phi}_{r \alpha}, \hat{\phi}_{r \beta}$ are the alpha and beta adaptive rotor flux components; 
The adaptation mechanism generates the value of the observer speed. It is based mainly on the hyperstability theory the conventional rotor flux MRAS scheme, this is performed by defining a speed tuning signal $\varepsilon_{\omega}$ to be minimized by a PI controller, which generates the observer speed that is feedback to the adaptive model. The error speed is the difference among the product of rotor flux of reference and adaptive model. The expressions for the speed tuning signal and the observer speed can be given as [3].

$$
\begin{aligned}
& \varepsilon_{\omega}=\phi_{r \beta} \hat{\phi}_{r \alpha}-\phi_{r \alpha} \hat{\phi}_{r \beta} \\
& \omega_{r}=\left(k_{p}+\frac{k_{i}}{p}\right)
\end{aligned}
$$

The velocity variant cross coupling due to speed rotor dependent components in the adaptive model can guide to an instability issue. Therefore, it is common for the rotor flux equation represented in the rotor reference frame to be used [22].

$$
\begin{aligned}
& \hat{\phi}_{r d}=\frac{L_{m}}{1+T_{r} p} i_{s d} \\
& \hat{\phi}_{r q}=\frac{L_{m}}{1+T_{r} p} i_{s q}
\end{aligned}
$$

where $\hat{\phi}_{r d}$ and $\hat{\phi}_{r q}$ are the rotor flux components all expressed in the rotor reference frame. The implementation of the rotor frame-based flux model is shown in Figure 2.

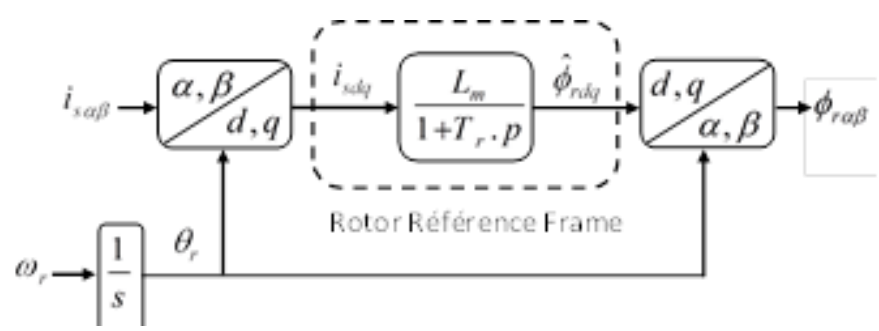

Figure 2. The Adaptaive model in the rotor reference frame

\section{THE PREDICTIVE MRAS SPEED OBSERVER}

The predictive MRAS speed observer (PMRAS) is developed from the Finite Control Set Model Predictive Control (FCS-MPC). The MPC is a modern digital control technique that offers a powerful tool to deal with control problems of power converters and electric drives. The main prominences of FCS-MPC are its compact design and flexibility to include many additional control targets. By considering only finite possible states of the inverter, solving the cost function would be straightforward.

The FCS-MPC use to design the adaptation mechanism in MRAS speed observer. An optimization problem is formulated to find the rotor position in order to minimize the speed tuning signal $\varepsilon_{\omega}$. The rotor position varied between 0 and $2 \pi$ continuously; a search technique discreted the rotor position into a limited number of positions to allow calculating the cost function at each of these discrete positions. The predictive MRAS observer is shown in Figure 3 [23],[24]. 


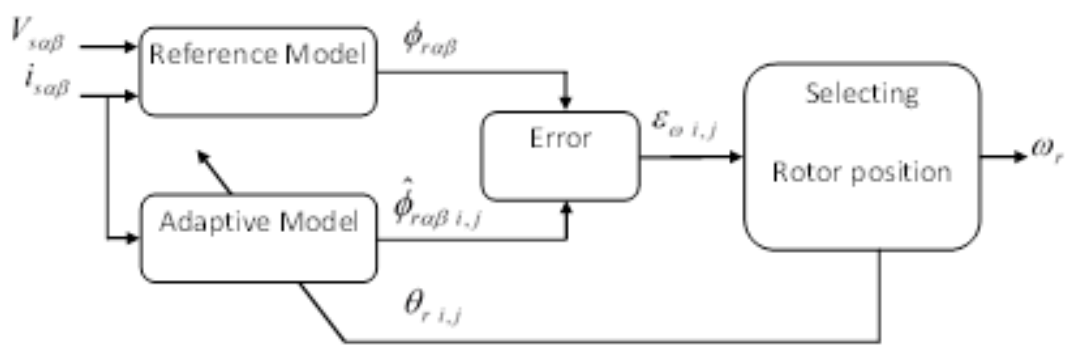

Figure 3. The predictive MRAS speed observer

The search algorithm is shown in Figure 4 starts by calculating the reference model outputs $\phi_{r \alpha}, \phi_{r \beta}$, also initializing the base angle $\theta_{b a s e}$ and the error speed $\varepsilon_{\omega}$, and calculating a displacement $\left(\Delta \theta_{i}\right)$ can be given as

$$
\Delta \theta_{i}=\frac{\pi}{4} \cdot 2^{-i}
$$

where $i$ is the order of the current iteration. The discrete rotor position as follows

$$
\theta_{i, j}=\theta_{b a s e}+\Delta \theta_{i} \cdot(j-4)
$$

where $j$ is the order of the displacement. Each discrete position $\theta_{i, j}$ used to calculate the adaptive model outputs corresponding to each individual position $\hat{\phi}_{r \alpha}, \hat{\phi}_{r \beta}$. Therefore, the cost function $\varepsilon_{i, j}$ is calculated for each position as follows:

$$
\varepsilon_{i, j}=\phi_{r \beta} \hat{\phi}_{r \alpha_{i, j}}-\phi_{r \alpha} \hat{\phi}_{r \beta_{i, j}}
$$

After eachs iteration, the search algorithm gets closer to the optimal solution, which produces the minimum cost function throughout the search space, is selected as the output rotor position of the observer. The speed signal get by the average value of the change in rotor position, dividing by the simple period as follows [14].

$$
\begin{aligned}
& \omega_{r}=\frac{2 \pi}{60} \frac{\Delta \theta_{\text {average }}}{t_{s}} \\
& \Delta \theta_{\text {average }}=\frac{1}{x} \sum_{n=1}^{x}\left(\theta_{\text {rotor }}(k)-\theta_{\text {rotor }}(k-1)\right)_{n}
\end{aligned}
$$

$\Delta \theta_{\text {average }}:$ The average value of the change in rotor position,

$x \quad$ : Recorded of the change in rotor position,

$t_{s} \quad$ : Simple period. 


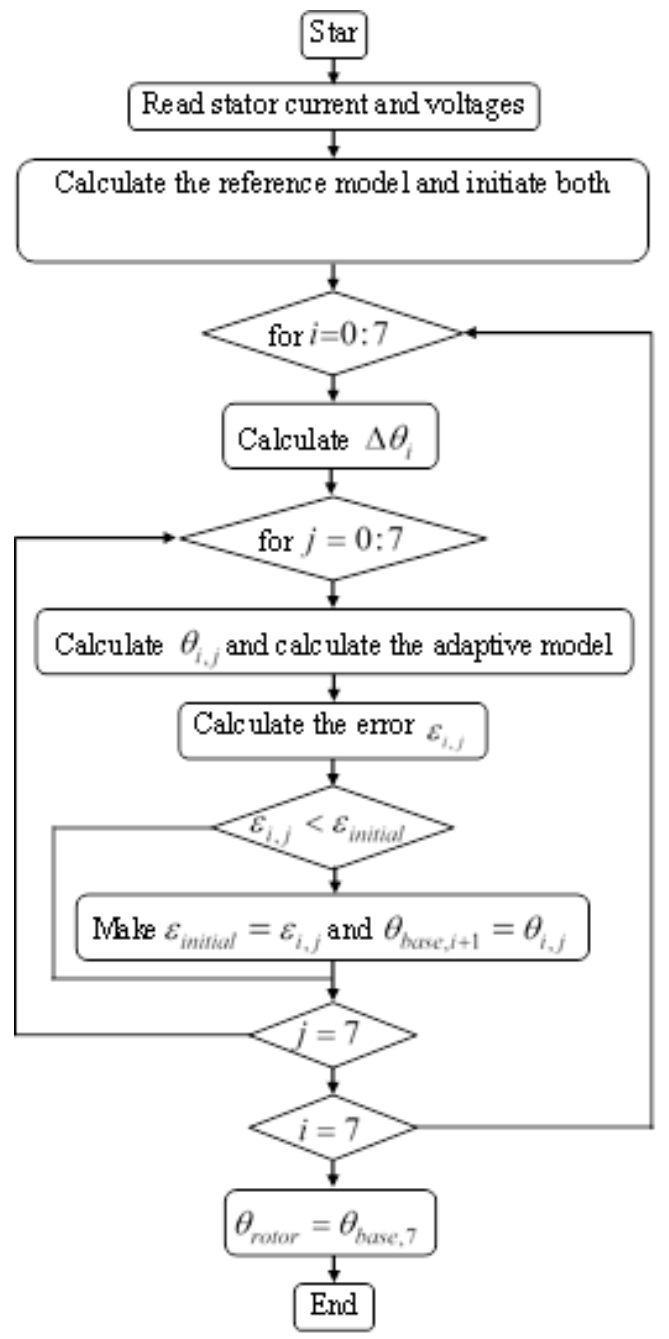

Figure 4. The rotor position search algorithm

\section{SIMULATION RESULTS AND DISCUSSIONS}

In this section, the simulate system used the induction machine, the IFOC scheme for vector control is driven by two observers speed, the classical rotor flux MRAS with PI controller, the gains are set to $\mathrm{Kp}=1000$ and $\mathrm{Ki}=10000$ which are tuned using trial error method to obtain the optimal dynamic performance, and the predictive MRAS with a search algorithm to ensure the sensorless and evaluate the comparative. Simulation results obtained in MATLAB/Simulink environment.The block diagram of sensorless induction motor drive with CMRAS/PMRAS speed observers show in Figure 5. The motor parameters are presented in Table 1.

Table 1. Induction Motor Paramètres

\begin{tabular}{lc}
\hline \multicolumn{1}{c}{ Designation } & Quantity \\
\hline Rated power & $1.5 \mathrm{~kW}$ \\
Rated voltage & $220 \mathrm{~V}$ \\
Rated speed & $1428 \mathrm{rpm}$ \\
Nominal frequency & $50 \mathrm{~Hz}$ \\
Stator resistance & $4.85 \Omega$ \\
Rotor resistance & $3.805 \Omega$ \\
Cyclic stator inductance & $0.274 \mathrm{H}$ \\
Cyclic rotor inductance & $0.274 \mathrm{H}$ \\
Mutual inductance & $0.258 \mathrm{H}$ \\
Number of pole pairs & 2 \\
Moment of inertia & $0.031 \mathrm{~kg} / \mathrm{m} 2$ \\
Friction coefficient & $0.00114 \mathrm{Nm} . \mathrm{s} / \mathrm{rd}$ \\
\hline
\end{tabular}

Int J Pow Elec \& Dri Syst, Vol. 9, No. 4, December 2018 : 1523 - 1533 


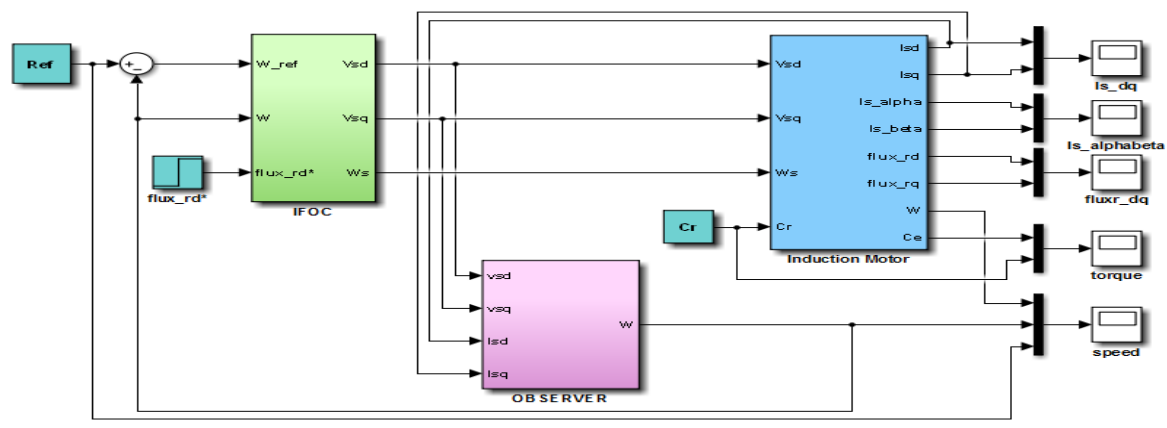

Figure 5. Block diagram of sensorless induction motor drive with CMRAS/ PMRAS speed observers

The simulation results presented and discussed from testes the performance of both observers under the following conditions:

- The speed reference star between times 0.5 and $1.5 \mathrm{~s}$ augmented from 0 to $100 \mathrm{rad} / \mathrm{s}$, then between times 3.5 and $4.5 \mathrm{~s}$ reduced from 100 to $0 \mathrm{rad} / \mathrm{s}$, next between times 5.5 and $6.5 \mathrm{~s}$ reversed from 0 to $-100 \mathrm{rad} / \mathrm{s}$ and finally between times 8.5 and $9.5 \mathrm{~s}$ augmented from -100 to $0 \mathrm{rad} / \mathrm{s}$.

- Zero speed between times 0 and $0.5 \mathrm{~s}$, also between times 4.5 and $5.5 \mathrm{~s}$, morover between times 9.5 and $10 \mathrm{~s}$.

- The load torque applying $10 \mathrm{Nm}$ between times 2 and $3 \mathrm{~s}$

- The change of rotor resistance up to $50 \%$ at time $2 \mathrm{~s}$.

- The change of stator resistance up to $50 \%$ at time $2 \mathrm{~s}$.

In Figure 6, illustrates the sensorless performance of induction motor drive with PMRAS observer, the rotor speed observer and reference depicted in (a), the rotor position generate from the search optimization alghorithm depicted in (b), phase current depicted in (c), d \& q axis stator currents depicted in (d), alpha \& beta axis rotor fluxes depicted in (e), the electromagnetic and load torque depicted in (f).

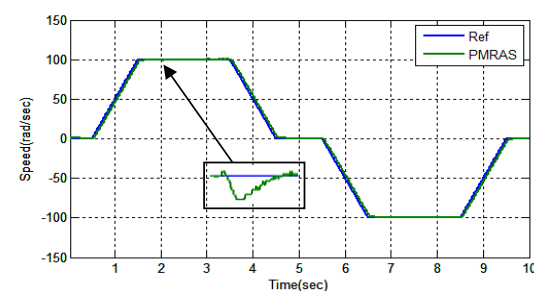

(a)

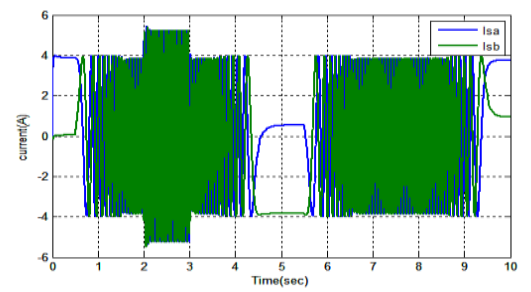

(c)

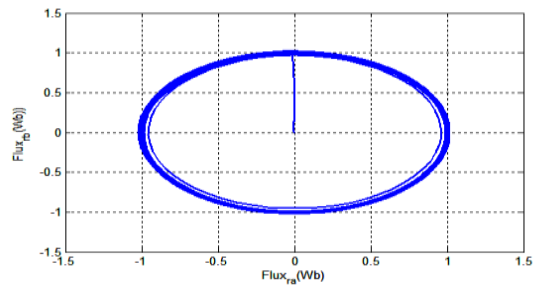

(e)

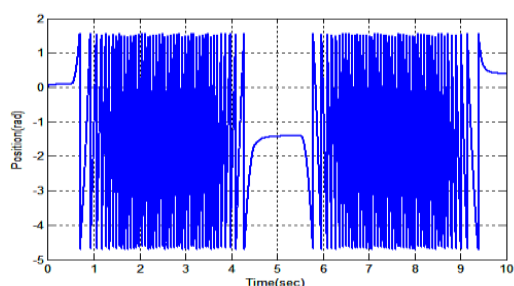

(b)

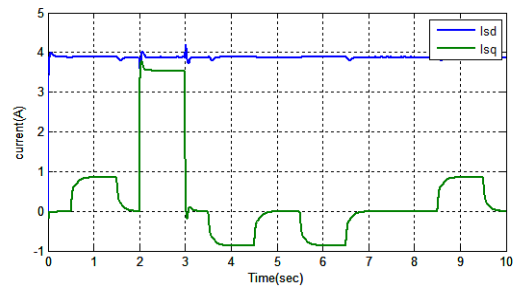

(d)

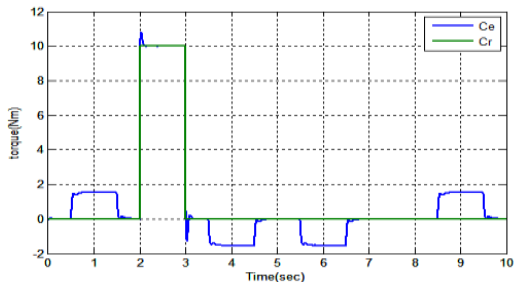

(f)

Figure 6. simulation results of sensorless performance of induction motor drive with PMRAS observer (a) rotor speed, (b) rotor position, (c) phase current, (d) d \& q axis stator currents, (e) alpha \& beta axis rotor fluxes, (f) torque 
According to these satisfactory results, the proposed observer show a high dynamic performance, the FOC control technique ensures a good regulation also a dynamic torque response and full decoupling between flux and torque. The rotor speed observed precise tracking the reference including low and zero speed, moreover robustness against a reversal speed, the load torque disturbance variation and very rapid rejection.

In Figure 7, illustrates the comparative sensorless performance of induction motor drive between CMRAS and PMRAS observers, the rotor speed observer of CMRAS, measured and reference depicted in (a), the rotor speed observer of PMRAS ,measured and reference depicted in (b), speed error of CMRAS depicted in (c), speed error of PMRAS depicted in (d).

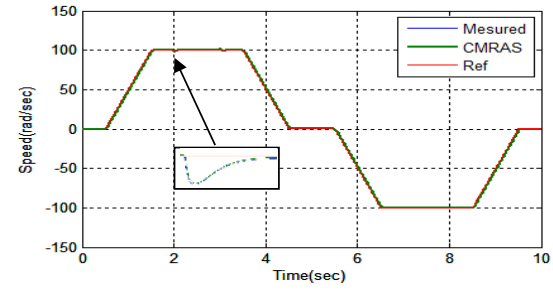

(a)

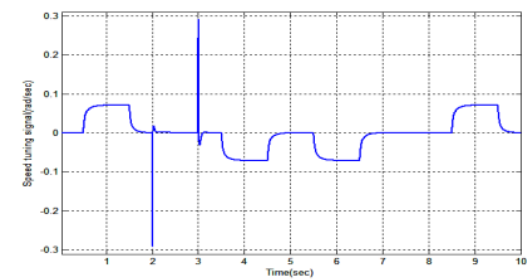

(c)

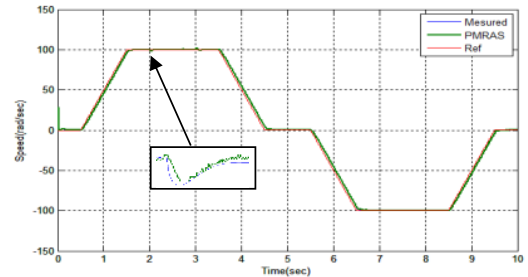

(b)

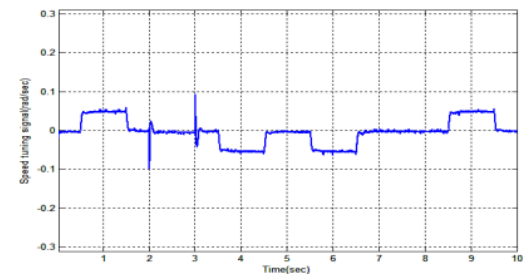

(d)

Figure 7. Simulation results of comparative sensorless performance of induction motor drive between CMRAS and PMRAS observers (a) rotor speed CMRAS, (b) rotor speed PMRAS, (c) speed error CMRAS, (d) speed error PMRAS

For this important results obtained, the PMRAS show superiority in comparison with CMRAS. The predictive observer proved a better tracking between the reference and the adaptive model; also reject the load torque three times faster than the CMRAS.

In Figure 8, illustrates the sensorless performance of induction motor drive with impact of rotor and stator resistances change, the rotor speed observer of CMRAS and reference depicted in (a,e), the rotor speed observer of PMRAS depicted in (b,f), speed error of CMRAS depicted in (c,i), speed error of PMRAS depicted in $(\mathrm{d}, \mathrm{j})$.

For this significant results, the PMRAS show again à better quality and performance, also high robustness against the rotor and stator resistances change. Figures 8(a) and (b) show the rotor speed of both observers work perfect. In Figures 8(c) and (d) show the PMRAS give a high robustness and more stability against the rotor resistance change. Figure 8(e) and (f) show again the PMRAS a better robustness against the stator resistance change with steady and less oscillations then the CMRAS. 


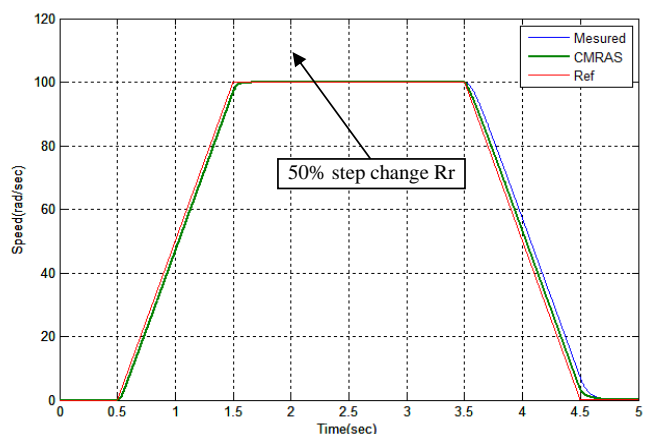

(a)

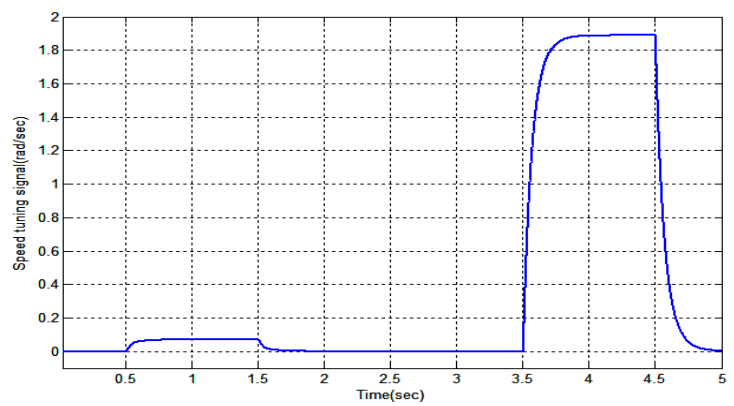

(c)

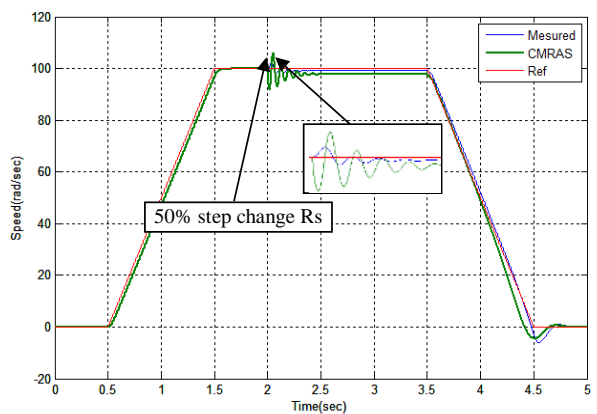

(e)

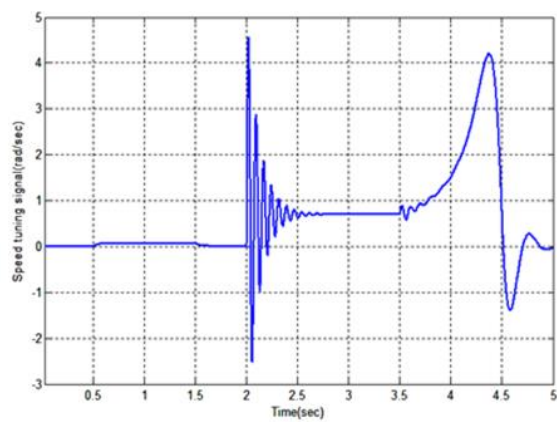

(i)

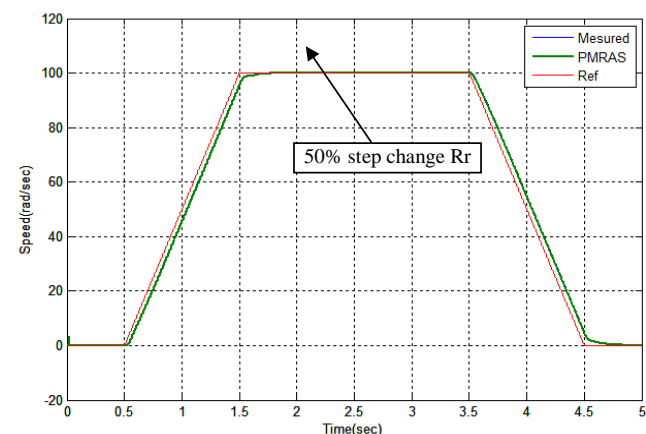

(b)

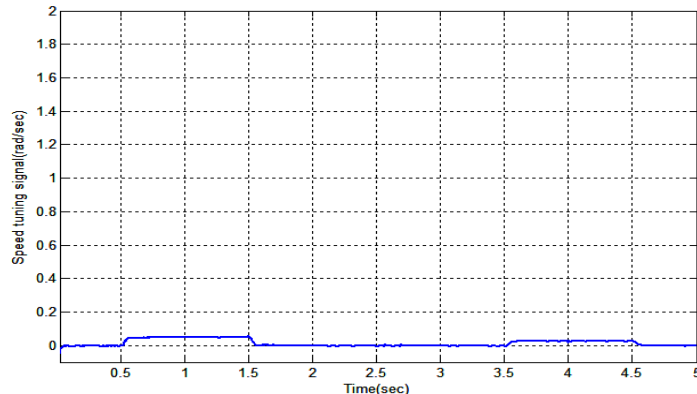

(d)

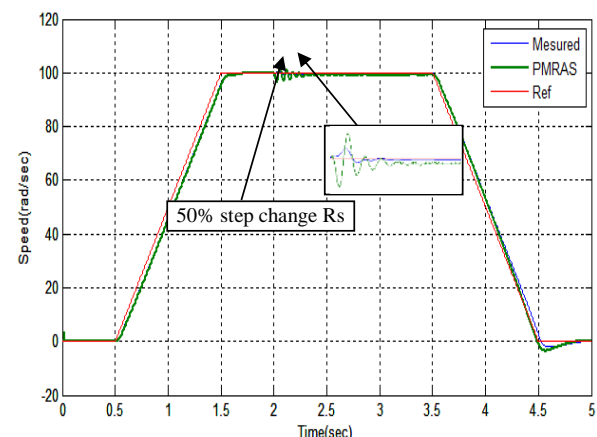

(f)

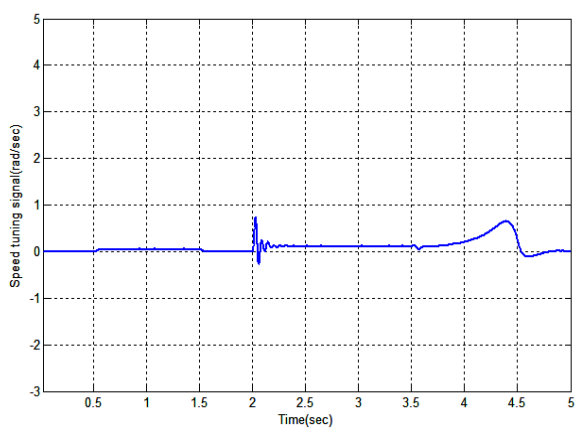

(j)

Figure 8. Simulation results of sensorless performance of induction motor drive with impact of rotor and stator resistances change. $(\mathrm{a}, \mathrm{e})$ rotor speed CMRAS, $(\mathrm{b}, \mathrm{f})$ rotor speed PMRAS, $(\mathrm{c}, \mathrm{i})$ speed error CMRAS, $(d, j)$ speed error PMRAS

\section{CONCLUSION}

In this paper, a predictive model reference adaptive system (PMRAS) rotor speed observer for sensorless induction motor drives has been presented. These models create from the classical MRAS rotor flux observer and the finite control set model predictive control (FCS-MPC). The success of this 
combination proved with the satisfactory simulation results, show clearly excellent observation and robustness against external disturbances and motor parameter variation under different operating conditions, especially at zero speeds.

\section{REFERENCES}

[1] B. Drury, "The Control Techniques Drives and Controls Handbook," London, U.K., Inst. Elect. Eng., 2001.

[2] J. W. Finch and D. Giaouris, "Controlled AC electrical drives," IEEEsTrans. Ind. Electron., vol/issue: 55(1), pp. 111,2008

[3] P. Vas, "Sensorless Vector and Direct Torque Control," London, U.K., Oxford Univ. Press, 1998.

[4] B. K. Bose, "Modern Power Electronics and AC Drives. New Delhi," India, Prentice-Hall, pp. 333- 435, 2006.

[5] Comanescu M. and Xu L., "Sliding mode MRAS speed estimators for sensorless vector control of induction machine," IEEE Trans. Ind. Electron., vol/issue: 53(1), pp. 146-153, 2006.

[6] Kwon Y. A. and Jin D. W., "A novel MRAS based speed sensorless control of induction motor," Proc. 25th Annu. Conf. IEEE Ind. Electron. Soc., pp. 933- 938, 1999.

[7] G. Imane, et al., "Neural Adaptive Kalman Filter for Sensorless Vector Control of Induction Motor," International Journal of Power Electronics and Drive System (IJPEDS), vol/issue: 8(4), 2017.

[8] J. W. Finch and D. Giaouris, "Controlled AC electrical drives," IEEE Trans. Ind. Electron., vol/issue: 55(1), pp. 1$11,2008$.

[9] M. Rashed and A. F. Stronach, "A stable back-EMF MRAS-based sensorless low speed induction motor drive insensitive to stator resistance variation," Inst. Electr. Eng. Proc. Electr. Power Appl., vol/issue: 151(6), pp. 685693, 2004.

[10] J. Guzinski and H. Abu-Rub, "Speed sensorless induction motor drive with predictive current controller," IEEE Trans. Ind. Electron., vol/issue: 60(2), pp. 699-709, 2013.

[11] P. Alkorta, et al., "Efficient multivariable generalized predictive control for sensorless induction motor drives," IEEE Trans. Ind. Electron., vol/issue: 61(9), pp. 5126-5134, 2014.

[12] F. Wang, et al., "Encoderless finite-state predictive torque control for induction machine with a compensated MRAS," IEEE Trans. Ind. Informat., vol/issue: 10(2), pp. 1097-1106, 2014.

[13] J. Ruan and S. Wang, "A prediction error method-based selfcommissioning scheme for parameter identification of induction motors in sensorless drives," IEEE Trans. Energy Convers., vol/issue: 30(1), pp. 384-393, 2015.

[14] Y. B. Zbede, et al., "Model Predictive MRAS Estimator for Sensorless Induction Motor Drives," IEEE Trans. Ind. Electron., vol/issue: 63(6), pp. 3511-3521, 2016.

[15] A. Alalei, et al., "Self-Tuning Fuzzy Based PI Controller for DFIM Powered by Two Matrix Converters," International Journal of Power Electronics and Drive System (IJPEDS), vol/issue: 7(3), 2016.

[16] A. Omari, et al., "dSPACE DS1104 Based Real Time Implementation of Sliding Mode Control of Induction Motor," International Journal of Power Electronics and Drive System (IJPEDS), vol/issue: 9(2), 2018.

[17] S. Huang, et al., "The vector control based on MRAS speed sensorless induction motor drive," Proc. World Congr. Intell. Control Automat., vol. 5, pp. 4550-4553, 2004.

[18] M. Montanari, et al., "Speed sensorless control of induction motor based on indirect field-orientation," Proc. Ind. Appl. Conf., vol. 3, pp. 1858-1865, 2000.

[19] C. Schauder, "Adaptive speed identification for vector control of induction motors without rotational transducers," IEEE Trans. Ind. Appl., vol/issue: 28(5), pp. 1054-1061, 1992.

[20] H. Mohammed and A. Meroufel, "Contribution to the Artifical Neural Network Speed Estimator in a Degraded Mode for Sensor-Less Fuzzy Direct Control of Torque Application Using Dual Stars Induction Machine," International Journal of Power Electronics and Drive System (IJPEDS), vol/issue: 5(4), 2015.

[21] M. Horch, et al., "MRAS-based Sensorless Speed Integral Backstepping Control for Induction Machine, using a Flux Backstepping Observer," International Journal of Power Electronics and Drive System (IJPEDS), vol/issue: 8(4), 2017.

[22] P. L. Jansen and R. D. Lorenz, "A physically insightful approach to the design and accuracy assessment of flux observers for field oriented induction machine drives," IEEE Trans. Ind. Appl., vol/issue: 30(1), pp. 101-110, 1994.

[23] S. Saeidi and R. Kennel, "A novel algorithm for model predictive control of AC electrical drives," Proc. 2nd Int. Elect. Drives Prod. Conf. (EDPC), pp. 78-84, 2012.

[24] S. A. Davari, et al., "An improved FCSMPC algorithm for an induction motor with an imposed optimized weighting factor," IEEE Trans. Power Electron., vol/issue: 27(3), pp. 1540- 1551, 2012. 


\section{BIOGRAPHIES OF AUTHORS}

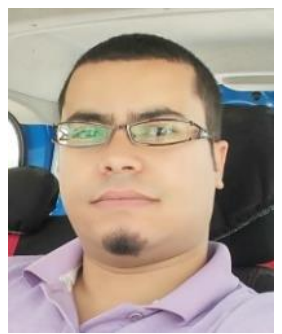

Zair Moustafa received the electrical engineering diploma from Bechar University, Algeria in 2010, and the Master degree from the Bechar University, Algeria in 2012. He's currently preparing his Ph.D degree. Where he is member of the Research Laboratory of Control Analysis and Optimization of the Electro-Energetic Systems (CAOSEE). His research interests include electric drives, process control, power electronics, observer and estimator design, artificial intelligence and their applications.

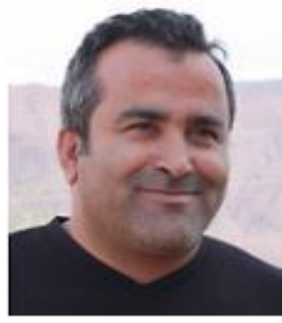

Hazzab Abdeldjebar received his State Engineer, MS, and PhD degrees in Electrical Engineering from the Electrical Engineering Institute of The University of Sciences and Technology of Oran (USTO), Algeria in 1995, 1999, and 2006, respectively. He is currently a Professor of Electrical Engineering at the University of Bechar (Algeria), where he has been the Director of the Research Laboratory of the Command, Analyses, and Optimization of Electro-Energetic Systems since 2009. His research interests include power quality, modeling, modern controller and observer design for nonlinear systems, control of power electronics, multidrive systems and electrical vehicle, and adaptive control and no-linear systems diagnostic. 